\title{
O TRANSPORTE POR CABOTAGEM NO BRASIL - POTENCIALIDADE PARA A INTERMODALIDADE VISANDO A MELHORIA DO FLUXO LOGÍSTICO
}

\section{THE COASTAL TRANSPORTATION IN BRAZIL - POTENTIAL FOR THE IMPROVEMENT OF AIMING INTERMODALITY LOGISTIC FLOW}

\author{
Delmo Alves de Moura *E-mail: delmo.moura@ufabc.edu.br \\ Rui Carlos Botter** E-mail: rcbotter@usp.br \\ *Universidade Federal do ABC - UFABC, Santo André, SP \\ **Escola Politécnica da Universidade de São Paulo, São Paulo, SP
}

\begin{abstract}
Resumo: Este trabalho descreve os aspectos relacionados com o sistema de cabotagem no Brasil (transporte marítimo costeiro), seus principais agentes, os fatores relacionados com a intermodalidade (transportes rodoviário, ferroviário, fluvial etc.), que corroboram para aumentar a competitividade logística e a eficiência do sistema de transporte, num país de dimensão continental.

O escopo do estudo é a revisão bibliográfica sobre o tópico cabotagem, analisá-lo no âmbito do cenário nacional e como este sistema está implantado em alguns países visando a intermodalidade. O cerne do estudo também está na análise da legislação vigente, que define os parâmetros para o sistema de transporte via cabotagem. O resultado do estudo mostra que é essencial a integração entre os sistemas de transportes no território doméstico e que a cabotagem possui um papel essencial no Brasil, além de poder contribuir para o segmento da construção naval brasileira.
\end{abstract}

Palavras Chave: Cabotagem. Intermodalidade. Competitividade. Sistema Logístico. Custos.

\begin{abstract}
This study describes aspects related to coastal shipping in Brazil and its main actors and intermodal factors (road, rail, fluvial transportation etc.) which corroborate to the increase of logistics competitiveness and efficiency of transportation in a large country like Brazil. The purpose of the study is bibliographic research on the topic, analyzing it inside the Brazilian scenario and also how it has been implemented in some countries. The objective of the study is also analyzing legislation which defines parameters to coastal shipping. This fact interferes directly with the logistics system and its intermodal aspects. If Brazil intends to reduce its logistics costs, coastal shipping should be an effective way to contribute to the Brazilian matrix of transport. Coastal shipping is supposed to bring competitive advantage and reduction of logistic costs. The conclusion is that integration is essential among the systems of domestic transportation and coastal shipping with its outstanding role in this environment, can contribute substantially to the Brazilian maritime industry.
\end{abstract}

Keywords: Cabotage. Intermodal. Competitiviness. Logistic System. Costs

\section{INTRODUÇÃO}

O Brasil possui dimensão continental e o transporte de produtos para todas as regiões deste país enfrenta barreiras, como as condições das estradas, que eleva o 
custo do transporte, reduzindo a competitividade, principalmente para o transporte de longa distância.

O transporte por via marítima na costa de um país, a cabotagem, é uma forma de tornar este modal competitivo para grandes distâncias num país com esta grande extensão territorial.

A cabotagem aliada aos demais modais de transportes, ferroviário, rodoviário e hidroviário, pode contribuir muito para redução dos custos logísticos nacionais, além de reduzir avarias de transporte, perda de carga etc.

A cabotagem é largamente utilizada na comunidade européia, nos Estados Unidos. O Brasil pode espelhar-se em algumas experiências bem sucedidas para alavancar este segmento de transporte, prover a intermodalidade e melhorar o nível de serviço prestado ao mercado.

Segundo o Regulamento para o Tráfego Marítimo (MEDINA, et al., 2010; PINTO et al., 2007; RTM, 1992), a navegação mercante pode ser classificada em:

- Longo curso: A realizada no tráfego marítimo mercantil entre os portos do Brasil e os portos estrangeiros.

- Grande cabotagem: A realizada no tráfego marítimo mercantil entre os portos brasileiros e entre estes e os portos da Costa Atlântica da América do Sul, das Antilhas e da Costa Leste da América Central, excluídos os portos de Porto Rico e Ilhas Virgens.

- Pequena Cabotagem: A realizada no tráfego marítimo mercantil entre os portos brasileiros, não se afastando a embarcação mais de 20 (vinte) milhas náuticas da costa e fazendo escala em portos cuja distância não exceda de 400 (quatrocentas) milhas náuticas. Considera-se também de pequena cabotagem a navegação realizada com fins comerciais entre a costa brasileira e as ilhas oceânicas brasileiras.

- Alto-Mar: A realizada fora da visibilidade da costa;

- Costeira: A realizada ao longo do litoral brasileiro, dentro dos limites de visibilidade da costa;

- Apoio Marítimo: A realizada entre os portos ou terminais marítimos e as plataformas tripuláveis. 
O armador não necessita de autorização da ANTAQ (Agência Nacional de Transporte Aquaviário) para afretamento de embarcações quando:

- A embarcação estiver registrada sob bandeira brasileira e

- A embarcação registrada sob bandeira estrangeira for afretada a casco nu (contrato ao qual o afretador tem a posse, o uso e o controle da embarcação, por tempo determinado).

A legislação brasileira considera normalmente a cabotagem como sendo (lei 10.893/04): "Navegação de cabotagem é aquela realizada entre portos brasileiros, utilizando exclusivamente a via marítima ou a via marítima e as interiores".

Como conhecida hoje, a cabotagem teve seu marco em 1890, quando a Companhia Lloyd Brasileiro começou a operar em navegação de cabotagem, de longo curso e interior.

\subsection{Escopo da Pesquisa}

O procedimento neste trabalho foi realizar uma revisão bibliográfica sobre o assunto, trata-se de uma pesquisa do tipo exploratória. O levantamento bibliográfico foi realizado em periódicos específicos da área, de congressos, de dissertações ou teses de doutoramento que abrangesse o assunto ou algo correlato, assim como alguns livros que tratam do tópico de forma direta ou indireta (PEREIRA, 1999; BABBIE, 2001; COOPER, SCHINDLER, 2003; GIL, 1991; SELLTIZ et al., 1981).

O foco da revisão bibliográfica foi caracterizar e discutir o tema cabotagem. Em seguida caracterizar sua intermodalidade, o que inclui os serviços portuários e a integração com os demais meios de transportes: ferroviário, rodoviário e fluvial dentro de uma abordagem da logística integrada.

\section{O Transporte de Cabotagem}

A evolução tecnológica do transporte marítimo mundial é decorrente de diversos fatores, dentre os quais, destacam-se: o acondicionamento de carga, o nível de especialização da embarcação, o porte da embarcação e o sistema de propulsão (STOPFORD, 2004). 
No transporte de cabotagem, a evolução tecnológica pode ser balizada a partir de cinco parâmetros:

1. Unitização da carga;

2. Nível de especialização das embarcações e porte;

3. Idade média da frota;

4. Modernização dos portos e

5. Serviços logísticos de apoio.

\subsection{Unitização da Carga}

Classicamente, a carga utilizada no transporte marítimo pode ser dividida em três grandes tipos: granel líquido (petróleo, derivados de petróleo etc.), granéis sólidos (minérios, grãos etc.) e carga geral (sacaria, contêineres, carga solta etc.).

Com o advento das modernas formas de acondicionamento de cargas, por exemplo, o contêiner, as cargas passaram a ser classificadas em seis categorias: granéis líquidos, granéis sólidos, cargas frigorificadas, sacaria, contêineres e carga geral, sendo que, de maneira genérica, as cargas continuaram a ser classificadas nos três tipos básicos.

A grande evolução tecnológica no acondicionamento de cargas foi 0 surgimento do contêiner em meados da década de 60. Devido à padronização de suas dimensões, os benefícios foram distribuídos ao longo de toda rede logística: facilidade para o exportador acondicionar a carga no local de origem, especialização de veículos de transporte terrestres (trens e caminhões), especialização da movimentação da carga nos terminais (centros de distribuição, portos etc.) e especialização das embarcações de transporte marítimo com o surgimento do navio porta-contêiner.

Com a mecanização dos portos e a inserção de equipamentos de bordo nas embarcações, os armadores são diretamente beneficiados com a redução do tempo no porto/terminal. Segundo Stopford (2004) uma embarcação típica de carga geral de 22.000 TPB ocupava $40 \%$ do seu tempo no porto, enquanto que um portacontêiner de 47.000 TPB - portanto uma embarcação com maior capacidade de carga - ocupava apenas $17 \%$ de seu tempo no porto. 
Essa forma de operação mais ágil do contêiner permitiu o aumento rápido do porte das embarcações (Gráfico 1), e as consequentes economias de escala: devese lembrar que o navio tem um custo fixo de aquisição elevado e ao transportar em uma escala maior esse custo fixo se dilui por um volume maior de carga, reduzindo o custo unitário de transporte. Outro aspecto relevante da unitização da carga em contêineres é a mudança na forma como o armador cobra o frete do usuário.

Gráfico 1 - Evolução do porte dos navios porta-contêiner

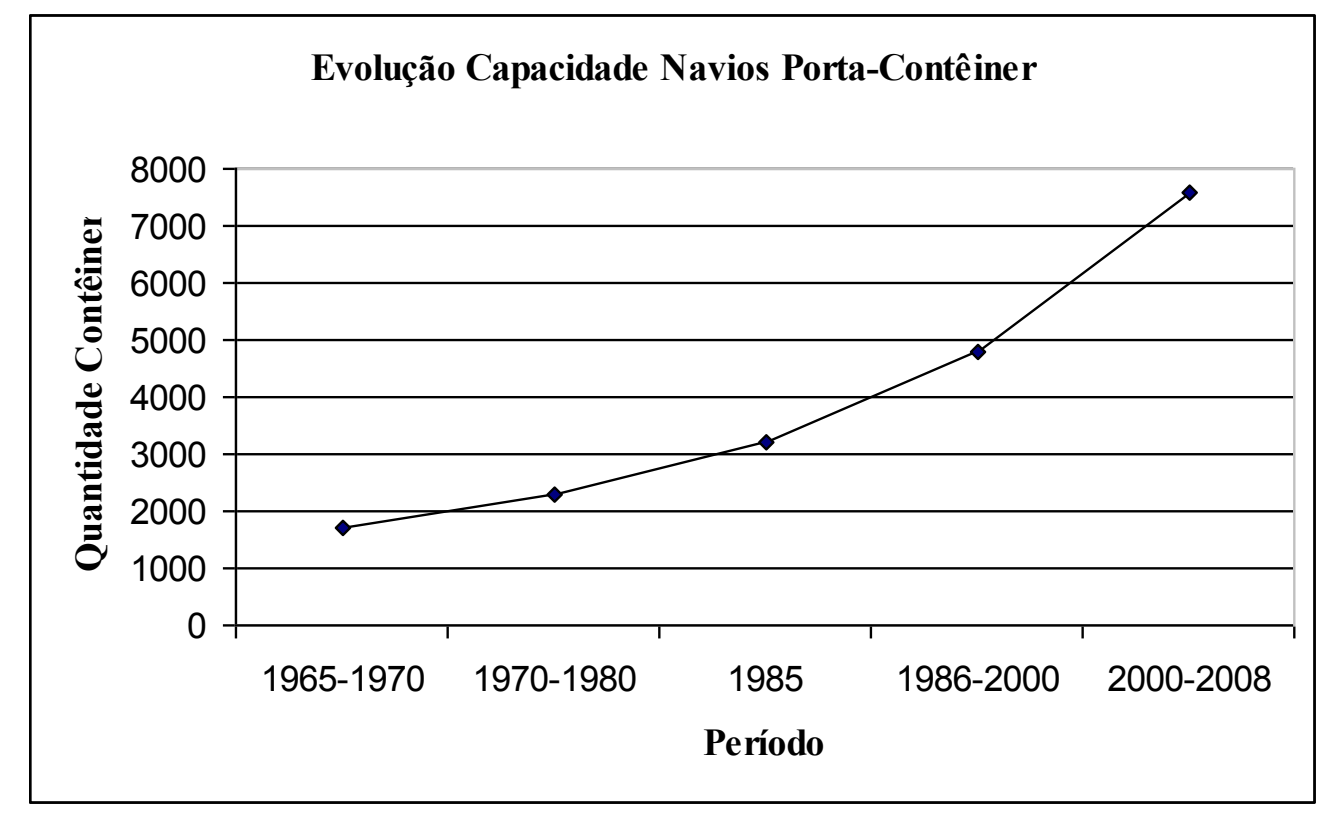

Fonte: (STOPFORD, 2004)

\subsection{Nível de especialização das embarcações}

A variação da capacidade de carga dos navios acompanha o aperfeiçoamento tecnológico. Explorando esta ideia, as embarcações aumentaram o seu porte através da especialização no transporte de um tipo de carga específico granéis sólidos, granéis líquidos e contêineres. Por outro lado, considerando que portos e terminais menores carecem de equipamentos, a dificuldade de movimentação de contêineres no ambiente portuário, seja pela falta de equipamentos adequados em número suficiente ou pelo custo do tempo de espera da embarcação no porto, propiciou o desenvolvimento de embarcações especializadas denominadas roll on/roll off (ro-ro). 
As embarcações ro-ro são especializadas no transporte de cargas que possuem rodas, como automóveis, reboques e semi-reboques de caminhões, e, geralmente, possuem uma rampa de acesso para estes veículos. Deste modo, diminuem-se as necessidades de equipamentos para movimentação de carga no porto e, principalmente, o tempo de operação portuária. As embarcações ro-ro são atrativas para o transporte de cabotagem, pois não necessitam de grandes investimentos portuários e reduzem o tempo de trânsito da carga.

Às vezes, uma embarcação porta-contêiner pode ser acessada através de uma rampa ro-ro, em portos sem equipamentos de transferência de contêineres.

A empresa Norsul, um armador, opera sob contrato da Aracruz Celulose no transporte de madeira de eucalipto entre o centro produtor localizado em Ponta de Areia, Caravelas-BA, e o centro consumidor em Barra do Riacho-ES. A empresa realiza a operação de transporte marítimo com navios-barcaças e empurradores, de modo semelhante à operação comumente feita em hidrovias por empurradores e chatas.

A vantagem desta operação é o fato de maximizar a utilização do empurrador, pois ele está a maior parte do tempo em operação de transporte, seja empurrando barcaças carregadas para Barra do Riacho, seja empurrando barcaças vazias para Caravelas. Outra vantagem é o fato deste tipo de operação exigir um número menor de tripulantes que um navio, menor consumo de combustível e dispensar o serviço de rebocadores.

Este tipo de inovação abre uma perspectiva para o transporte de cabotagem de curtas distâncias, que pode substituir com larga economia o transporte rodoviário.

\subsection{Modernização dos portos}

Em 1993 foi sancionada a Lei de Modernização dos Portos (lei 8.630), que modernizou a gestão portuária, por meio da criação do Conselho de Autoridades Portuária - CAP e do Órgão de Gestão de Mão-de-Obra - OGMO, e transferiu a operação de terminais para o setor privado. O resultado desse processo, iniciado pela Lei dos Portos, foi o surgimento de novos e consistentes investimentos em infraestrutura e melhoria do desempenho operacional dos portos, com a consequente redução dos custos portuários. A navegação de cabotagem foi 
beneficiada como foi todo o transporte marítimo. Em particular, portos eficientes para a movimentação de contêineres são uma condição fundamental para que esse tipo de carga seja atraída para a cabotagem. Contudo, se é correto afirmar que houve reduções de custos nos principais portos, também é correto afirmar que o sistema portuário brasileiro ainda não atinge níveis de produtividade semelhantes àqueles praticados nos portos estrangeiros (FADDA, 2007).

\subsection{Serviços logísticos de apoio}

A unitização de carga facilitou o transporte e permitiu que empresas de navegação pudessem oferecer o transporte porta-a-porta (Figura 1). Dada a complexidade deste tipo de operação algumas empresas especializaram-se neste tipo de serviço, surgindo então os operadores logísticos. Hoje, as empresas possuem a disposição, além dos operadores logísticos, os centros de consolidação de carga, onde a carga de diversas empresas é consolidada, ou seja, unitizada em contêineres que assim são transportados por via marítima ao porto de destino. $\mathrm{Na}$ origem, a carga é re-unitizada de modo que cada cliente receba o seu produto corretamente. Este tipo de operação, além da economia de escala gerada, é um facilitador que aumenta o potencial de atração de cargas do modal marítimo (MEDINA, et al., 2010).

Figura 1 - Representação do uso de centro de consolidação de carga para transporte marítimo

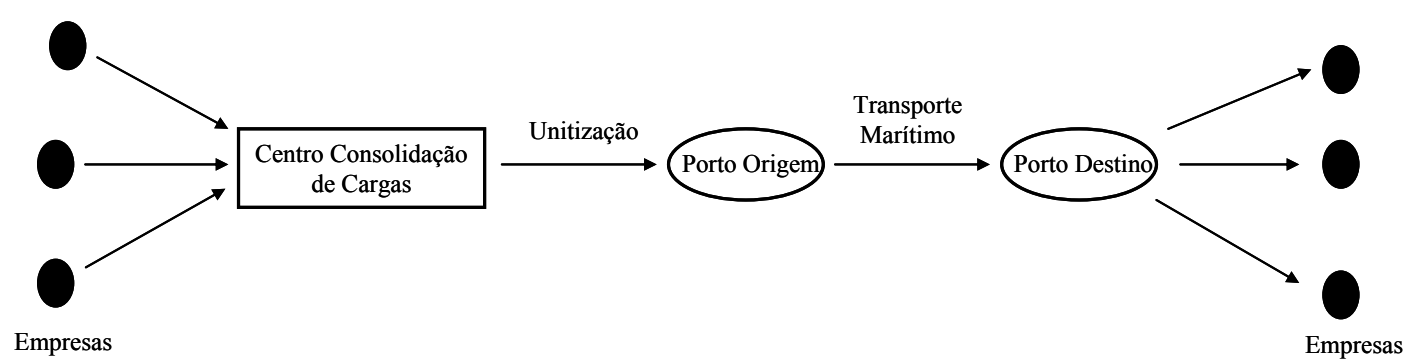

Fonte: Adaptado de Medina, et al. (2010). 


\subsection{A concorrência e sinergia com outros modais}

O modal marítimo enfrenta uma concorrência muito forte como o modal rodoviário, pelo transporte de carga no Brasil. A maior parte da carga transportada no país é por via rodoviária, aproximadamente $62,6 \%$ da totalidade. A política de transporte vigente favorece o transporte rodoviário em detrimento do transporte marítimo de cabotagem.

No Brasil o transporte rodoviário caracteriza-se por ter maior velocidade em distância intermediária, maior oferta e frequência de viagens. O modal ferroviário corresponde com aproximadamente $19,9 \%$ do transporte de carga, o modal aquaviário com $12,8 \%$, o dutoviário com $4,4 \%$ e o aéreo com $0,3 \%$.

O modo marítimo de cabotagem perdeu competitividade nos fretes devido ao desenvolvimento do modo rodoviário, através da construção e manutenção de rodovias, do desenvolvimento tecnológico dos veículos e dos subsídios aos combustíveis, dado pelo governo Federal, ocorrido nas décadas de 50 e 90 (MOURA; BOTTER; MEDINA, 2007).

É necessário aproveitar o potencial que cada modal pode contribuir para uma operação integrada de transporte nacionalmente. A operação de transporte multimodal é caracterizada por um único contrato de transporte. Utilizam-se duas ou mais modalidades de transporte, desde a origem até o destino. Esta tarefa é executada sob a responsabilidade única de um Operador de Transporte Mutimodal OTM. Este operador é uma empresa contratada para realização do transporte multimodal da carga da origem até o destino, por meios próprios ou por intermédio de terceiros.

O Transporte Multimodal de Cargas compreende, além do transporte em si, os serviços de coleta, consolidação, movimentação e armazenagem de carga, desconsolidação e entrega, enfim, todas as etapas indispensáveis à completa execução da tarefa (VANHERLE, DELHAYE, 2010).

Para atuar nos mercados potenciais é fundamental possuir frequência e confiabilidade dos serviços prestados, minimizar os custos intermodais, possuir uma visão logística de equipe, com controle das operações, sistemas integrados, estrutura intermodal própria ou terceirizada, terminais intermodais e tomada de decisão integrada. 


\section{MODELOS DE POLÍTICA MARÍTIMA NO BRASIL}

A política marítima é definida como um conjunto de ações econômicas, legais e administrativas pelo qual o Estado influencia a posição da sua frota mercante nos mercados nacional e internacional de fretes. As ações ditas econômicas são aquelas que agem nas atividades comerciais das empresas participantes do mercado de navegação, enquanto as ações de ordem legal ou administrativa são aquelas que procuram regular e regulamentar o mercado interno de navegação (FADDA, 2007; CHRZANOWSKI, 1985).

As linhas mestras da política marítima de uma nação devem ser estabelecidas pelo governo central, que deve considerar não só as demandas econômicas dos setores de transporte, comércio e indústria de construção naval, mas também, as questões de soberania nacional e de segurança militar (HODGSON, BROOKS, 2004; STURMEY, 1965; WEBB, 2004):

- Promover e proteger a marinha mercante por motivos de segurança;

- Estabelecer uma marinha mercante capaz de transportar os produtos essenciais do país, de modo a evitar interrupções do abastecimento devido às guerras em que o país não está participando;

- Satisfazer ao prestígio da nação;

- Viabilizar uma marinha mercante jovem, a qual, eventualmente, não dependerá de assistência ao atingir a estabilidade no futuro;

- Fomentar as trocas e comunicações com outras nações, principalmente entre os territórios coloniais;

- Economizar na importação de serviços de frete;

- Prover empregos para a marinha mercante nacional;

- Proteger a marinha mercante nacional em períodos de competição severa;

- Conter práticas discriminatórias reais ou suspeitas das conferências ou grupos econômicos nacionais;

- Incrementar a qualidade da frota da marinha mercante e sua competitividade e, 
- Compensar os armadores nacionais por sobretaxas mantidas por outros propósitos ou por desvantagens impostas na navegação por políticas de proteção industrial.

A relação de objetivos pode ser dividida em dois grandes grupos: os objetivos de ordem econômica e os de ordem não-econômica. Estes objetivos não são, necessariamente, contraditórios entre si, mas interdependentes: os objetivos militares ou estratégicos redefinem os objetivos econômicos e vice versa (BROOKS, 2006; CHRZANOWSKI, 1985).

Com fins meramente ilustrativos, podem-se classificar as ações de política marítima em quatro grandes categorias:

- Políticas de direitos e deveres;

- Políticas de proteção ambiental;

- Políticas de segurança da navegação e,

- Políticas de regulação e desenvolvimento de mercado.

Sendo o mercado de transportes marítimos um mercado internacional por sua natureza, as ações de política marítima devem considerar este mercado como determinante de suas ações.

Em países em desenvolvimento como o Brasil, que necessitam do incremento do comércio exterior para seu desenvolvimento econômico, a política marítima deve garantir a oferta de embarcações disponíveis para transporte e estar atenta ao crescimento da necessidade por esse transporte. Exemplificando, o que se viu no passado recente com a desregulamentação do setor de longo curso, foi a diminuição da participação de embarcações de bandeira brasileira no total transportado em longo curso, criando uma situação de risco e dependência para o comércio exterior.

\section{MECANISMOS DE PROTEÇÃO E INCENTIVOS ATUAIS: REDEFININDO A CABOTAGEM}

As políticas para o mercado nacional - como a cabotagem - não podem ser dissociadas da realidade do mercado de transportes internacional. Para que a navegação de cabotagem seja viável e competitiva dentro do mercado de 
navegação, ela deve atender às medidas de competitividade usuais a qualquer setor econômico: custo e nível de serviço.

No transporte marítimo, o custo é traduzido como o frete cobrado, e o nível de serviço é traduzido por suas diversas características desejáveis: frequência da rota, especialização do navio, tecnologia empregada, velocidade etc. Um modelo de política marítima que atenda à navegação de cabotagem deve, portanto, incluir as ameaças externas decorrentes do mercado internacional, que podem ser resumidas em três grandes ameaças (HODGSON, BROOKS, 2007):

- Custo fixo de aquisição da embarcação mais baixo;

- Custo variável de operação da embarcação (mão-de-obra, combustível etc.) mais baixo e,

- Embarcações tecnologicamente mais avançadas (velocidade, tamanho, especialização etc.).

Atualmente, a navegação de cabotagem brasileira dispõe de dois grandes mecanismos de proteção e incentivo: a reserva de bandeira e o depósito de $R \$ 0,75$ para cada $\mathrm{R} \$ 1,00$ depositado na conta vinculada que o armador possui no Fundo de Marinha Mercante (previsto pela lei 10.893 para vigorar até 2011). Os mecanismos de proteção e incentivo estão intrinsecamente ligados à política de construção naval vigente (MEDINA, et al., 2010).

Quanto à proteção à bandeira, este é um mecanismo de proteção usual no mercado de transporte marítimo internacional. As nações adotam alguma forma de proteção à bandeira. O bloco de países formado por: Grécia, Japão, Noruega, Estados Unidos e Alemanha adotam a proteção à bandeira e que, ao mesmo tempo, detêm cerca de $50 \%$ da TPB mundial. Na visão liberal, contudo, a reserva de bandeira é considerada um entrave para o desenvolvimento e as nações são incentivadas a adotar a liberalização da cabotagem (BROOKS, 2009a; OECD, 2001; CHLOMOUDIS et al., 2007).

O incentivo à cabotagem por meio de depósito na conta vinculada, garante ao armador uma renda adicional, que tanto pode ser entendida como uma política compensatória pela obrigação de se utilizar estaleiros nacionais na construção e 
reparo das embarcações, quanto como um incentivo à renovação da frota no curto prazo - afinal, nos termos da lei 10.893, o incentivo deverá ser extinto em 2011.

As políticas aplicadas contemporaneamente são, portanto, de ordem protecionista e econômica. Tais políticas estão comprometidas com um modelo pensado para a indústria de construção naval: a proteção à bandeira garante demanda para as embarcações que por sua vez garante demanda para os estaleiros nacionais. Esse modelo pode e deve ser questionado à luz da realidade da complexidade do transporte de cargas atual: a existência da cabotagem não depende apenas da existência da embarcação (construída no estaleiro) e da existência da companhia de navegação (cliente do FMM), ela depende dos terminais de transporte, dos outros modais de carga, dos terminais de consolidação de carga etc. Portanto, deve-se pensar a cabotagem não mais como o transporte de carga por via marítima entre cabos, mas como: uma cadeia logística de transporte de cargas que utiliza em um dos seus elos o transporte marítimo entre pontos da costa brasileira.

Colocada sob essa definição mais ampla, estimular a cabotagem não se limita a estimular um dos braços de transporte (o marítimo), mas estimular toda a cadeia. A cabotagem, como definida aqui, pode ser esquematiza como na Figura 2. $\mathrm{Na}$ figura, reforça-se a natureza multimodal do problema, pois a carga que chega ou parte do elo de transporte regional pode fazê-lo por qualquer um dos modais (MEDINA, et al., 2010).

Figura 2 - Representação esquemática da cabotagem

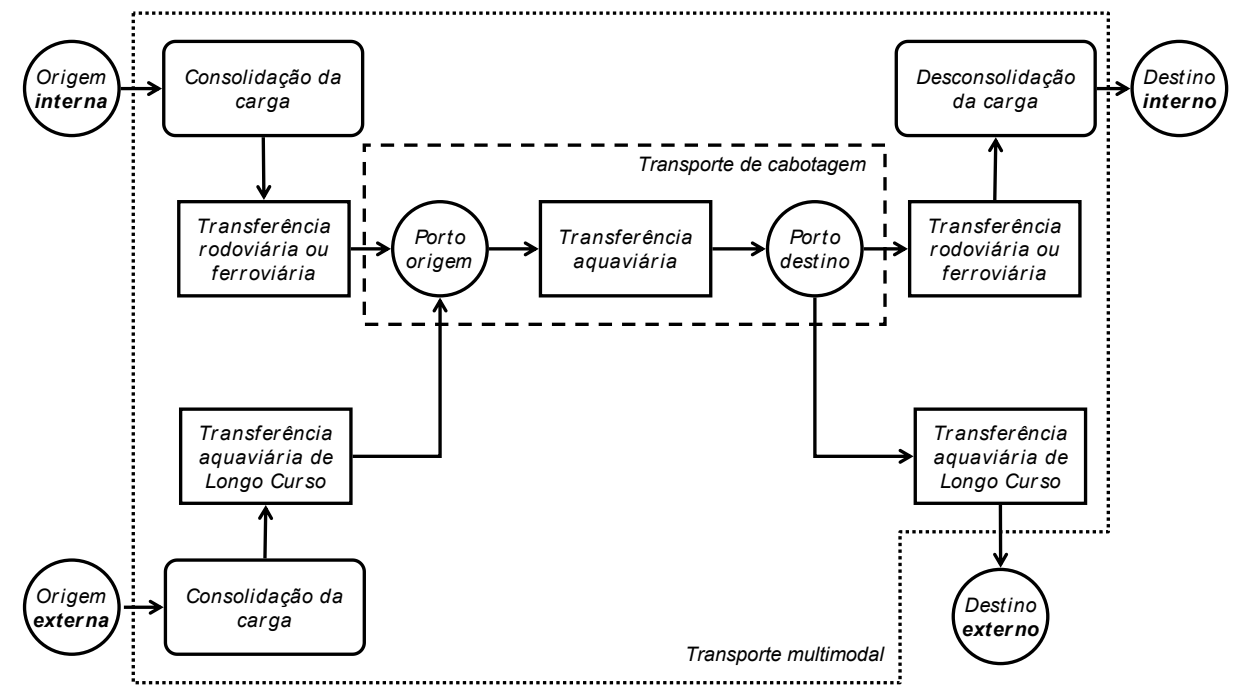

Fonte: (MEDINA, et al., 2010).

Revista Produção Online. Florianópolis, SC, v.11, n. 2, p. 595-617, abr./jun., 2011. 
Assim, as políticas de incentivo e de regulação devem ser cuidadosas para nem privilegiar um elo em detrimento dos outros, nem esquecer os aspectos concorrenciais existentes em cada elo (MEDDA, PELS, 2010; VISCUSI, VERNON, HARRIGTON, 1995).

Portanto, os mecanismos de incentivos atuais podem ser considerados adequados, face às políticas adotadas pelas nações e às necessidades da indústria de construção naval, contudo, certamente, não são suficientes para o estímulo ao transporte de cabotagem, pois esquecem de considerar toda a cadeia logística (MBIYDZENYUY, PERSSON, 2010).

A cabotagem deve ser entendida, portanto, como um meio de transporte multimodal. O conceito de multimodalidade está associado com ideia de um único responsável pelo transporte da carga (BENDALL; BROOKS, 2010).

Assim, as ações de apoio ao transporte de cabotagem devem ser inicialmente focadas em toda a cadeia de transporte e, em uma fase posterior, aos elos da cadeia.

O objetivo básico do OTM é, aproveitando a economia de escala gerada, aumentar a velocidade da operação e reduzir os desperdícios relativos aos estoques em trânsito, produtividade dos veículos, burocracia etc.

Dois aspectos ainda comprometem a implementação plena do OTM no Brasil: a forma de cobrança do ICMS e o seguro de carga. No caso do ICMS, a cobrança é fracionada entre os estados (quando o estado de origem é diferente do estado de destino) e sujeita às normas e resoluções específicas de cada estado, algumas vezes conflitantes. No caso do seguro da carga, a Resolução 794 de 23 de novembro de 2004 da ANTT regulamentou a questão, permitindo que o OTM negocie apólices de seguro por trecho. Essa decisão viabilizou a existência do OTM no Brasil. Contudo, o Brasil ainda não dispõe de uma apólice de seguro única para a carga, como é comumente encontrada no exterior. A principal razão para isso é o desinteresse das operadoras de seguro nessa forma de apólice.

A política marítima pode inserir-se dentro de um modelo de política industrial para o setor de navegação. Neste caso, acrescentam-se ao modelo, objetivos de desenvolvimento industrial, redução da dependência externa, desenvolvimento tecnológico, dentre outros. Surge assim, a necessidade de um balanço entre decisões de curto e longo prazo, muitas vezes conflitantes entre si. Outros conflitos 
podem surgir entre os atores do mercado, notadamente no caso brasileiro, a presença do AFRMM cria um estado de conflito entre armadores, estaleiros e usuários do serviço de transporte:

- Ao armador interessam embarcações ao menor custo de capital, e não a obrigação de construir embarcações nos estaleiros nacionais, mas, sim a reserva de bandeira e o AFRMM;

- Ao usuário interessa o menor frete, portanto não interessa a reserva de bandeira ou o AFRMM, mas interessa a oferta perene de embarcações para suas cargas $\mathrm{e}$

- Ao estaleiro interessa a obrigatoriedade da produção de embarcações em estaleiros nacionais e o AFRMM, mas não interessa a competição com estaleiros internacionais.

\section{ALGUMAS EXPERIÊNCIAS INTERNACIONAIS NA CABOTAGEM}

\section{$\checkmark \quad$ União Européia}

Algumas características geográficas e econômicas favorecem o transporte aquaviário no continente europeu:

- Mais de $67.000 \mathrm{~km}$ de costa;

- De $60 \%$ a $70 \%$ dos centros industriais europeus encontram-se a uma distância da costa que oscila entre 150 e $200 \mathrm{~km}$, possibilitando um fácil acesso ao transporte marítimo;

- Possui uma rede de $25.000 \mathrm{~km}$ de vias navegáveis interiores, que movimentam mais de 430 milhões de toneladas/ano;

- Possui conexões fluviais diretas com os portos de mar e com os portos interiores da União Européia, dos países escandinavos e dos países da Europa Central e Oriental e têm acesso a diversos portos interiores, tais como: Estrasburgo, Paris, Lyon, Liége, Gand e Bruxelas (TASTO, 2010, BROOKS, 2009b, ØDERGARD, KVINGUE, 2010). 
No âmbito da União Européia, a cabotagem é definida pelo Transporte Marítimo de Curta Distância - TMCD que é o tráfego marítimo de carga e passageiros entre portos da UE ou a eles ligados por mares interiores. A regulamentação do setor é baseada em dois regulamentos da Comissão das Comunidades Européias - CEE (BROOKS, 2009a):

- Regulamento (CEE) n. ${ }^{4}$ 4055/86 art. 1, do Conselho - Consagra a liberdade de prestação de serviços de transportes marítimos internacionais na Comunidade;

- Regulamento (CEE) n. ${ }^{\circ} 3577 / 92$ do Conselho - Prevê que o princípio da livre prestação de serviços de cabotagem marítima é aplicado na Comunidade a partir de 1 de Janeiro de 1993, suprimindo os obstáculos jurídicos da concorrência.

Basicamente, o mercado de cabotagem europeu é cativo de toda embarcação registrada em qualquer um dos seus países membros. Todas essas condições tornam o mercado de cabotagem europeu o mais desenvolvido do mundo. Um ponto que se destaca é simplificar as regras de funcionamento dos portos e agrupar todos os agentes da cadeia logística (carregadores, armadores e transportadores).

Assim, a UE já trabalha a problemática da navegação de cabotagem a partir de uma perspectiva integrada.

O foco principal está na integração do sistema, com o objetivo de se concretizar as chamadas "auto-estradas" do mar. As "auto-estradas" do mar deverão descongestionar os principais pontos de estrangulamento terrestres do sistema europeu de transportes e reforçar a integração logística do transporte marítimo de curta distância. Ela é definida como o segmento marítimo que liga dois portos, interligados por sua vez com as redes transeuropéias e os corredores intermodais, que salvaguardando a coesão social, configuram um sistema intermodal eficiente onde as mercadorias são rapidamente transferidas entre os modais através da otimização das operações portuárias, superando as barreiras naturais e as áreas sensíveis assim como outros obstáculos geográficos.

A ideia central do projeto é a da substituição do transporte rodoviário: 
- Baseadas em corredores marítimos desenvolvidos para se assumirem como uma alternativa em termos de preços e parâmetros de serviço aos corredores rodoviários e,

- Permitir melhorar os níveis de acessibilidade às regiões mais periféricas da Europa (BROOKS, 2009b).

A experiência européia de compartilhamento do mercado de cabotagem pode ser considerada um sucesso do ponto de vista da oferta de serviços de transportes. Esse tipo de situação deve ser observado com atenção pelos países da América Latina, pois pode significar uma alternativa para o desenvolvimento dos seus mercados regionais.

\section{$\checkmark \quad$ América do Norte}

Na América do Norte a cabotagem é influenciada pela regulação do Canadá e dos Estados Unidos. Estes países resolveram isolar a navegação doméstica.

No Canadá há diferentes departamentos e agências com suas próprias prioridades definindo as políticas de navegação. Em toda costa canadense somente embarcações de bandeira nacional podem realizar o transporte de cabotagem. A embarcação de bandeira canadense deve ter tripulação, também, canadense com certificados disponibilizados somente para cidadão canadense ou residente permanente no Canadá. Uma empresa de navegação internacional, mesmo localizada no Canadá fisicamente, não poderá atuar na navegação de cabotagem (BROOKS, FROST, 2004).

Nos Estados Unidos da América (USA) a cabotagem é regida pela lei Jones Act. A embarcação deve ser construída nos USA, a tripulação de ser norteamericana e o proprietário da embarcação, empresa de navegação, deve ser uma empresa nacional (BROOKS, FROST, 2004).

$A$ regulação do mercado de cabotagem norte-americano garante às embarcações de bandeira nacional o direito de transportar carga e passageiros entre portos nacionais.

O transporte de cabotagem é regulamentado basicamente por duas leis: o Passenger Act e o Jones Act. O Passenger Act foi criado em 1986 e estabelece que 
nenhuma embarcação estrangeira pode transportar passageiros entre portos norteamericanos, sob pena de multa. O Jones Act foi criado em 1920 e estabelece, na sua forma atual, que os produtos transportados entre portos norte-americanos devem ser realizados por embarcações construídas e documentadas nos Estados Unidos e que o proprietário e a tripulação sejam formados por $75 \%$ de cidadãos norte-americanos. O Jones Act foi concebido a partir da necessidade de uma marinha mercante que fosse capaz de garantir o transporte de grande parte dos produtos e que pudesse ser utilizado para uso militar em caso de guerra ou emergência nacional (LEWARN, FRANCIS, 2009; MAGEE, 2002).

As grandes barreiras para o desenvolvimento da cabotagem apontadas pelos operadores do sistema (GAO, 2005) são:

- O custo de capital das embarcações produzidas nos estaleiros nacionais e

- A taxa de manutenção portuária.

O custo de capital mais elevado é decorrente da obrigatoriedade da construção de embarcações nos estaleiros nacionais, estabelecida no Jones Act. A taxa de manutenção portuária é um valor $(0,125 \%)$ cobrado sobre o valor da carga e utilizado nas operações de manutenção portuária, como a dragagem.

O DOT (Department of Transportation) - é o órgão governamental responsável pelo planejamento do sistema de transportes nacional. Atualmente, o DOT considera a cabotagem como uma de suas maiores prioridades, motivada pelas necessidades de aumento da mobilidade de carga e redução de congestionamentos. Dentro da estrutura do DOT encontra-se a Maritime Administration - MARAD, uma agência de promoção de fomento dos transportes marítimos. Com o objetivo de promover a navegação de cabotagem, em 2003, foi criado o SCOOP - Short Sea Shipping Cooperative Program, uma programa que reúne membros do governo (particularmente da MARAD) e da sociedade, para juntos identificarem meios de desenvolver a cabotagem norte-americana. A perspectiva de crescimento da cabotagem americana nos próximos anos será determinada por sua capacidade de atrair cargas de outros modais. 
Na maioria dos países da América Latina há uma legislação que protege o transporte de cabotagem. Esta legislação impõe a necessidade de que o serviço de cabotagem seja realizado por armadores nacionais, com navios de bandeira de cada país e com tripulação contratada sobre as leis de ditos países. Desta forma um navio de bandeira Chilena não pode fazer nenhum tipo de serviço de cabotagem unindo portos do Peru assim como nenhum navio de bandeira Argentina pode fazer transportes de cabotagem entre portos brasileiros e vice-versa.

Os acordos bilaterais de transporte marítimo entre Brasil, Chile e Argentina, e a reserva de bandeira adotada na cabotagem criam diversas ineficiências no sistema de transporte da região, por exemplo, (BAIRD et al., 2002):

- Uma embarcação chilena na rota Valparaíso (Chile) - Buenos Aires (Argentina) - Santos (Brasil) não pode transportar cargas de Buenos Aires para o Porto de Santos, pois isso desrespeitaria o acordo bilateral entre Brasil e Argentina. Uma embarcação argentina também não pode movimentar entre Santos e Valparaíso pelo mesmo motivo;

- Uma embarcação brasileira na rota Valparaíso - Punta Arenas (Chile) Puerto Madryn (Argentina) - Buenos Aires - Santos - Fortaleza não pode transportar cargas de Valparaíso e Punta Arenas ou entre Puerto Madryn e Buenos Aires, pois estaria rompendo a regra de reserva de bandeira. As mesmas restrições de cabotagem se aplicam para embarcações da Argentina ou Chile navegando em outros países.

Um aspecto característico do fluxo de mercadorias na região é o uso intensivo do modal rodoviário, em parte explicado pelas dificuldades que os países encontram no desenvolvimento do seu setor de cabotagem.

\section{CONCLUSÃO}

A situação brasileira reflete os dois grandes modelos de política marítima existentes nas nações: o protecionista e o liberal. No modelo protecionista, o 
governo toma várias ações intervencionistas afetando a liberdade de escolha do transportador de carga doméstico ou estrangeiro. Já no modelo liberal, existe total liberdade de escolha de qual será o transportador de carga, doméstico ou estrangeiro. A opção brasileira pelo modelo protecionista é característica das nações em desenvolvimento, que não possuem marinhas mercantes fortes. Contudo, o modelo protecionista também é adotado pelos Estados Unidos, como meio de garantir a competitividade de sua frota mercante.

É importante notar que a influência do liberalismo no mercado de transportes marítimos é questionável, pois as nações que advogam hoje a abertura do transporte marítimo são, em sua maioria, nações que criaram marinhas mercantes fortes por meio de políticas protecionistas no passado.

O primeiro passo é reconhecer que uma política para o setor de cabotagem deve considerar toda a rede logística de transportes e não apenas um dos elos, que é o transporte marítimo.

A UE possui atualmente o sistema de cabotagem mais desenvolvido no mundo. Em parte pelas suas facilidades costeiras e fluviais, mas, em grande parte pelo processo de integração econômica que abriu o mercado para todos os países membros.

Os Estados Unidos preveem o crescimento da cabotagem a partir da sua necessidade crescente de transporte, do consequente congestionamento do modal rodoviário e da necessidade de redução do consumo de combustíveis fósseis.

Sem dúvida, o exemplo da UE é um referencial para a integração econômica da América Latina, em particular entre os países do Mercosul. A reserva de bandeira praticada por Brasil, Chile e Argentina, impede o surgimento de rotas regionais que poderiam ganhar economia de escala ao incorporar o transporte de mercadorias de outros países do bloco e, portanto, melhorar o nível de serviço de transportes na região.

Feita de modo organizado e corrigindo-se eventuais assimetrias, a abertura do mercado de cabotagem nos moldes da UE pode significar mais um passo rumo à integração das nações latino-americanas, como historicamente desejaram seus povos e grandes líderes.

Alguns pontos essenciais para o desenvolvimento do setor são: 
- Pensar a cabotagem sempre de modo integrado aos diversos modais, e como um serviço porta-a-porta;

- Regulamentar o processo de transbordo de cargas de modo a desburocratizar procedimentos e facilitar o surgimento de serviço feeder para o Brasil e a América Latina;

- Investir em tecnologia de informação para integrar modais, facilitar o acompanhamento e o desembaraço da carga e permitir a tomada de decisão otimizada pelo transportador de carga;

- Investir na integração de sistemas de comunicação entre os portos latinoamericanos visando o serviço feeder e um possível mercado integrado no médio prazo;

- Realizar campanhas institucionais sobre as vantagens do transporte de cabotagem para o usuário e para operadores de transportes interessado em entrar no setor;

\section{REFERÊNCIAS}

BABBIE, E. Métodos de pesquisa de survey. Belo Horizonte: Editora UFMG, 2001.

BAIRD, A.; HOFFMANN, J.; WILMSMEIER. The Chilean Maritime Highway. ANNUAL CONFERENCE OF THE INTERNATIONAL ASSOCIATION OF MARITIME ECONOMISTS. IAME, Panama, 2002.

BENDALL, H.; BROOKS, M. R. Short sea shipping: lesson for or from Australia. ANNUAL CONFERENCE OF THE INTERNATIONAL ASSOCIATION OF MARITIME ECONOMISTS. IAME, Lisbon, July, 2010.

BROOKS, M. R.; FROST, J. D. Short sea shipping: a canadian perspective. Maritime Policy Management, 2004.

BROOKS, M. R. The Jones act under NAFTA and its effects on the Canadian shipbuilding industry. Atlantic Institute for Market Studies - AIMS. Dalhousie University, Atlantic Institute for Market Studies, Halifax, Nova Scotia, September, 2006.

Short sea developments in Europe: lessons for Canada. North American Transportation Competitiveness Research Council. CPCS Transcom, No 10, July, 2009a. 
. Liberalization in maritime transport. Intermodal Transport \& Supply

Chains. International Transport Forum - Transport for a Global Economy.

Challenges and Opportunities in the Downturn, 26-29 May, Leipzig, 2009b.

CHLOMOUDIS , C. I., PALLIS P. L., PAPADIMITRIOU S., TZANNATOS E. S. The liberalisation of maritime transport and the island regions in EU. Evidence from Greece. European Transport, n. 37, p. 1-15, 2007.

CHRZANOWSKI, I. Introduction to shipping economics. London: Fairplay Publications, 1985.

COOPER, D.; SCHINDLER, P. Métodos de pesquisa em administração. 7. ed. Porto Alegre: Bookman, 2003.

FADDA, E. A. Considerações sobre o transporte marítimo de cabotagem no Brasil. CONGRESSO PAN-AMERICANO DE ENGENHARIA NAVAL, TRANSPORTE MARÍTIMO E ENGENHARIA PORTUÁRIA, 20. 2007. São Paulo, 2007.

GAO. Short Sea Shipping options showa importance of systematic approach to public investment decisions. Washington: United States Government

Accountability Office. Report to the Senate Committee on Commerce, Science, and Transportation and the House Committee on Transportation and Infrastructure. GAO-05-768, 2005.

GIL, A. C. Como elaborar projetos de pesquisa. São Paulo: Atlas, 1991.

HODGSON, J. R. F., BROOKS M. R. Canada's Maritime Cabotage Policy: A report for transport Canada, Halifax: Marine Affairs Program, 2004.

Towards a north American cabotage regime: A Canadian

perspective. Canadian Journal of Transportation, v.1, n. 1, 2007.

LEWARN, B.; FRANCIS, J. Salvaging and developing a national flag fleet: A review of the contemporary maritime policies of some advanced industrial nations. Maritime Transport Policy Centre, AMC, August 2009. Disponível em:

<http://www.amc.edu.au/sites/default/files/MTPC+Occasional+Paper+2 0.pdf>. Acesso em: 24 abr. 2011.

MAGEE, K. U.S. Cabotage laws: protective or damaging? A strategy to improve cruise vessel competitiveness and traffic to U.S. ports. Dissertação (Mestrado). Monterey Institute of International Studies, 2002.

MBIYDZENYUY, G.; PERSSON, J. A decision support method for analysing a short sea shipping link from a port infrastructure perspective. ANNUAL CONFERENCE OF THE INTERNATIONAL ASSOCIATION OF MARITIME ECONOMISTS, IAME, Lisbon, July 2010. 
MEDDA, F. R.; PELS, E. Incentive mechanisms for the development of short sea shipping. ANNUAL CONFERENCE OF THE INTERNATIONAL ASSOCIATION OF MARITIME ECONOMISTS, IAME, Lisbon, July, 2010.

MEDINA, A. C.; MOURA, D. A.; FAVARIN, J. V. R.; PINTO, M. M. O.; BOTTER, R. C. Análise da competitividade da indústria marítima brasileira e um panorama do setor de cabotagem no Brasil e no exterior: uma visão da indústria da construção naval brasileira e seus principais atores. São Paulo: Iglu, 2010.

MOURA, D. A.; BOTTER, R. C.; MEDINA, A. C. Diagnosis of Brazilian short-sea shipping and it main obstacles. In: INTERNATIONAL CONGRESS OF THE INTERNATIONAL MARITIME ASSOCIATION OF MEDITERRANEAN, 12. 2007. IMAM: Taylor \&Francis, v. 1. p. 593-592, Varna, Bulgary, 2007.

ØDERGARD, A. M. KVINGUE, T. Protectionism or legitimate protection: on public regulation of pay and working conditions in Norwegian maritime cabotage. FAFO Report, Oslo, August, 2010. Disponível em:

<http://fafo.no/pub/rapp/20174/20174.pdf>. Acesso em: 23 abr. 2011.

PEREIRA, J. C. R. Análise de dados qualitativos: estratégias metodológicas para as Ciências da Saúde, Humanas e Sociais. São Paulo: Edusp, 1999.

RTM. Regulamento de tráfego marítimo. Rio de Janeiro: Diretoria de Portos e Costas, 1992.

PINTO, M. M. O.; COLIN, E. C.; FAVARIN, J. V. R.; AKAO, D. R. P. L.; ANDERSON, V. L. Legislação de cabotagem no Brasil: oportunidades e entraves para a indústria de construção naval. CONGRESSO PAN-AMERICANO DE ENGENHARIA NAVAL, TRANSPORTE MARÍTIMO E ENGENHARIA PORTUÁRIA, 20. São Paulo, Brasil, 2007.

SELLTIZ, C.; WRIGHTSMAN, L.S.; COOK, S.W. Métodos de pesquisa nas relações sociais. São Paulo: E.P.U./Edusp, 1981.

STOPFORD, M. Maritime economics. 2 ed. London: Routledge, 2004.

STURMEY, S.G. National Shipping Policies. The journal of Industrial Economics, v.14, n.1, p.14-29, 1965.

TASTO, M. Changing traffic patterns in North european shortsea container traffic. ANNUAL CONFERENCE OF THE INTERNATIONAL ASSOCIATION OF MARITIME ECONOMISTS, IAME, Lisbon, July, 2010

VANHERLE, K. DELHAYE, E. Road versus short sea shipping: comparing emissions and external costs. ANNUAL CONFERENCE OF THE INTERNATIONAL ASSOCIATION OF MARITIME ECONOMISTS, IAME, Lisbon, July, 2010.

VISCUSI, W. K., VERNON, J. M., HARRIGTON, Jr. J. E. Economics of regulation and antritrust. 2. ed. Boston: MIT Press, 1995. 
WEBB, R. Coastal shipping: an overview coastal: economics, commerce and industrial relations section. Information and Research Services Parliamentary Library. Research Paper, n. 12, 2003-04, 3 May 2004. Disponível em:

<http://202.14.81.34/library/pubs/RP/2003-04/04rp12.pdf>. Acesso em: 24 abr. 2011.

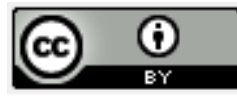

Artigo recebido em 15/12/2010 e aceito para publicação em 11/06/2011. 